\title{
MÁRGENES DE LA MÚSICA El horizonte y el otro en la experiencia musical
}

\author{
Borders of Music: The Horizon and the Other in Musical Experience
}

\author{
JAVIER ARES Yebra
}

Universidad de Vigo / Academia Argentina de Artes y Ciencias de la Comunicación, España / Argentina

\begin{tabular}{|c|c|}
\hline KEY WORDS & ABSTRACT \\
\hline $\begin{array}{l}\text { Music } \\
\text { Communication } \\
\text { Other } \\
\text { Horizon } \\
\text { Ethics }\end{array}$ & $\begin{array}{l}\text { The sound recording and reproduction systems and the development } \\
\text { without precedents of communication technologies consitute decisive } \\
\text { elements for thinking music nowadays. In this context, the present article } \\
\text { brings into dialogue two questions. In the first place, the question of the } \\
\text { essence of music from the conquest of ubiquity with the appearance of } \\
\text { Internet. Secondly, the question about the other in musical experience, } \\
\text { addressing the concert as a communicative situation. }\end{array}$ \\
\hline PALABRAS CLAVE & RESUMEN \\
\hline $\begin{array}{l}\text { Música } \\
\text { Comunicación } \\
\text { Otro } \\
\text { Horizonte } \\
\text { Ética }\end{array}$ & $\begin{array}{l}\text { Los sistemas de grabación y reproducción sonora y el desarrollo sin } \\
\text { precedentes de las tecnologías de la comunicación constituyen elementos } \\
\text { decisivos para pensar la música en la actualidad. En este contexto, el } \\
\text { presente artículo pone en diálogo dos cuestiones. En primer lugar, la } \\
\text { pregunta por la esencia de la música a partir de la conquista de la } \\
\text { ubicuidad con la aparición de Internet. En segundo lugar, la pregunta } \\
\text { por el otro en la experiencia musical, abordando el concierto como } \\
\text { situación de comunicación. }\end{array}$ \\
\hline
\end{tabular}

Recibido: $16 / 04 / 2020$

Aceptado: 26/06/2020

\section{GLOBAL KNOWLEDGE}




\section{Preludio}

$\mathrm{V}$ ivimos en un mundo saturado de redes, pantallas, señales acústicas y símbolos. Internet y las nuevas tecnologías de la comunicación han transformado radicalmente las relaciones entre arte y sociedad. Hasta la aparición de los sistemas de grabación y reproducción de sonido, la música se enmarcaba en un cara-a-cara del que nacía un particular sentimiento de comunidad. Al escuchar ahí, manteníamos con ella una relación empírica, si se quiere, más viva. El mundo de la hipercomunicación ha puesto en jaque su primigenia función ritual, esto es, convocar, jugar a ser con otros.

Con el objetivo de sentar algunas bases para un posterior y más amplio desarrollo, esta propuesta explora la pregunta por el lugar en el que acontece la obra musical a partir de «la conquista de la ubicuidad» (Valery, 1999) -su presencia inmediata o su reproducción en cualquier momento y espacio- como elemento determinante en esta especie de devenir música del mundo. Cuestionando la inamovilidad material del aura -en sentido benjaminiano-, sujeta a la experiencia estética como realidad irrepetible, se examina la tesis de la intersubjetividad como el "lugar" donde acontece, finalmente, la música.

Para ello, se aborda la obra musical como horizonte temporal. Se reflexiona sobre el concierto como situación de comunicación (situación que llamaré «La música va a comenzar»), examinando su potencial para configurar un otro-lugar, la inauguración de un nuevo horizonte propio. En la búsqueda de una articulación con el mundo, la idea de horizonte en la experiencia musical se revela memoria, movimiento, expectativa, cuerpo. Todo converge, en definitiva, en el otro.

\section{Pensar la música}

Ponderando su potencial interés en el marco de una filosofía de la música, el presente texto bosqueja y pone en diálogo dos cuestiones. En primer lugar, la pregunta por la esencia de la música, entendiendo por esencia su naturaleza, aquello invariable que hace que la música sea lo que es. Y en segundo lugar, siguiendo una especie de «pacto autobiográfico» (Lejeune, 1975) la pregunta por el otro en el contexto de la experiencia musical.

¿Dónde reside la esencia de una obra musical? ${ }^{1}$ ¿Corresponde a los músicos pensar sobre ello o se trata, más bien, de una tarea filosófica? ¿Se puede hablar de la música de otro modo que no sea a través de metáforas? ¿Es posible reconocer en ella un nivel de significado equiparable al lenguaje de las palabras?

Buena parte de los campos del conocimiento ha intentado encontrar un sentido teórico y práctico al fenómeno musical. Descubrimos referencias en obras de metafísica, educación, religión y medicina; en tratados de poética, retórica o matemáticas; en trabajos literarios y en ensayos de estética (Lippman, 1964). Los estilos, acercamientos y modos de practicar la música son, hoy, innumerables.

En la historia de la música occidental es conocida la anécdota, referida por Steiner (2007, 2012), en la que se le preguntó a Robert Schumann acerca del significado de una de sus composiciones después de haberla interpretado. En lugar de responder, el maestro alemán se sentó de nuevo al piano y la interpretó por segunda vez. Esto permite plantear una dificultad a la hora de pensar la música que sintetizaré en lo siguiente: la música es, ante todo, una experiencia ${ }^{2}$. Pero ¿de qué tipo? En definitiva, la acción de Schumann invita a reflexionar sobre «[...] la inevitable incompletitud y parcialidad de un discurso sobre la música pronunciada por un músico [...]» (Berio, 2019, p. 11) cuando este opta exclusivamente por las palabras para traducir el espejismo semántico de una obra musical y obvia la utilización del sonido en su respuesta.

La necesidad de abordar la experiencia musical de una forma paralela, complementaria, a partir de la especulación conceptual, tiene precedentes muy antiguos. La curiosidad que despierta el concepto mismo de música es permanente a lo largo de la historia: de su

\footnotetext{
1 Tomo aquí como punto de partida el artículo «Where is the essence of a musical work?» (2019), del Prof. Per Dahl (Universidad de Stavanger, Noruega).

2 Para una ampliación sobre la relación arte-experiencia, véase por ejemplo Art as Experience, de John Dewey (1934). En este fundamental texto, el autor concibe el arte como un proceso cuyo elemento principal ya no es el objeto artístico, la obra en su caráter de cosa, sino justamente el desarrollo de una experiencia.
} 
relación con la catarsis en Aristóteles a la scientia bene modulandi en San Agustín; del oculto ejercicio artimético de Leibniz, al oculto ejercicio metafísico de Schopenhauer; de la expresión del absoluto en Hegel, a su incapacidad para expresar en Stravinsky.

\section{Particularidades de la obra musical}

Además de su carácter de experiencia y de la dificultad de definirla -definir, delimitar y especificar un sentido constituye, seguramente, uno de los principales problemas a la hora de hacer investigación-, la música presenta otras particularidades que la configuran como un arte abstracto, íntimo y profundamente emotivo. Me referiré a ellas como las "cuatro naturalezas":

1. Naturaleza no-representacional. Cuando escuchamos música aparece el espejismo de un contenido semántico porque, como señala Heidegger, «somos nosotros los que oímos, no el oído. Oímos sin duda a través del oído, mas no con el oído. [...] Nuestro oír y ver [...] no son nunca un recibir meramente sensible» (1991, pp. 87-89). La superación de la necesidad de conceptos permite a la música acercarse a la expresión simbólica de lo real. Schopenhauer lo expresó bellamente cuando dijo que «la música es la melodía cuyo texto es el mundo» (1998, p. 194) . Su ambigüedad es precisamente una parte de su privilegio como práctica comunicativa. Los sonidos musicales no pueden señalar el mundo. Son incapaces de nombrar la realidad en un sentido propositivo del término. La música no argumenta, no nos brinda un "asunto". No puede afirmar o mentir. Escapa a lo que los filósofos llaman las funciones de verdad. Si no señala la realidad mundana, si como declaró Stravinsky, «la música es incapaz de expresar nada en concreto» (2005, p. 67), ¿cómo es posible que nos interpele tan profundamente?

2. Naturaleza simbólica. Aunque el carácter de cosa, tal y como señalaba Heidegger, es inseparable de la obra de arte, esta posee algo que la distingue del resto: su capacidad para erigirse en símbolo. "La esencia de la música involucra, por tanto, la capacidad humana de crear sentidos simbólicos a partir de cualquier impresión» (Dahl, 2019, p. 197). Como declaró Stravinsky en sus
Conversaciones con Robert Craft: «Las notas siguen siendo intangibles. No son signos, sino símbolos» (Craft, 1991, p. 173).

3. Naturaleza mediada. ¿Dónde es la obra musical? 0 más precisamente, ¿dónde existe la música? A partir de esta pregunta, propongo desarrollar la idea de instancias múltiples para referirme a sus diferentes formas simultáneas: la idea del compositor, la partitura (notación), el concierto (ejecución), la grabación (re-producción), y la percepción por por parte del oyente (escucha). Plantear la música como una "constelación de mediaciones» (Born, 2011) es pensarla desde sus múltiples textualidades. Desde este punto de vista, el de sus instancias múltiples, la música no es más que pura mediación. A esta propiedad ya se refirió Adorno (2003) cuando hablaba de las «interminables mediaciones» del fenómeno musical. Combinando esta idea de mediación con la «invención de la tradición» de Hobsbawm (2013), sugiero que la historia de la música no es sino exterioridades: inventamos la tradición musical justamente desde esas mediaciones, desde los artefactos, documentos y trazas que nos quedan ${ }^{3}$.

4. Naturaleza temporal. En el proceso de escucha, la música despliega su capacidad para generar una suerte de tiempo propio, al que llamaré "tiempo musical". Debido a su naturaleza perecedera y fugaz, Adam de Fulda, la concibió como meditatio mortis en su tratado publicado en 1490, esto es, «la meditación constante sobre la muerte» (en Fubini, 2008, p. 219). No es posible eludir el carácter eventual de su existencia. Una vez que la música comienza, parece imposible recapitular, repasar. En ella solo hay devenir. Expresión de lo inefable, meditatio mortis y tempus fugit conviven naturalmente en la experiencia musical. Como sugiere Deleuze, la música es una anti-memoria ${ }^{4}$.

\footnotetext{
3 Se percibe el carácter deliberado en la construcción de cada tradición musical, por ejemplo, la preponderancia e invisibilización de determinados elementos o personajes. En este sentido, un caso paradigmático y sintomático es el de las mujeres compositoras a lo largo de la historia, cuestión que solo recientemente ha comenzado a tratarse con el rigor necesario.

4 La idea de música como anti-memoria en relación con el pensamiento de Deleuze se presenta de manera explícita en Le temps de la voix (Charles, 1976, p. 268). Para entrar a la idea
} 


\section{La aparición de los sistemas de grabación y reproducción sonora}

La presencia de música en la vida diaria ha venido aumentando en proporción al desarrollo de nuevos entornos comunicativos y herramientas tecnológicas. Un paseo por una calle de cualquier ciudad es suficiente para observar que vivimos en un mundo sobrecargado de señales acústicas y jingles.

La llegada de los sistemas de grabación y reproducción sonora ha tenido consecuencias decisivas para el arte. «La conquista de la ubicuidad», título del ensayo escrito por Paul Valery en 1928, reconfigura la pregunta por el lugar en el que acontece la obra de arte: los avances tecnológicos hacen posible su presencia inmediata o su reproducción en cualquier momento y espacio.

En 1935, en su texto sobre La obra de arte en la época de su reproductibilidad técnica, Walter Benjamin ${ }^{5}$ señala que:

Por primera vez en la historia del mundo, la reproductibilidad técnica de la obra de arte libera a esta de su existencia parasitaria dentro del ritual. Las obras artísticas más antiguas sabemos que surgieron al servicio de un ritual primero mágico, luego religioso. Con otras palabras: el valor único de la auténtica obra artística se funda en el ritual en el que tuvo su primer y original valor útil (2003, pp. 49-51).

Este giro tecnológico ha sido especialmente determinante en el ámbito musical. Asistimos a una especie de devenir música del mundo, pero en forma de una saturación sonora que, a menudo de manera indiscriminada, inunda cualquier escenario de la vida cotidiana. Este panorama no es el resultado de un énfasis en el encuentro empírico con el otro sino, más bien, de una progresiva virtualización en las relaciones humanas que no se inició con Internet, sino que:

[...] precede a la existencia de las nuevas tecnologías de comunicación y de reproducción de imágenes del siglo XX. La sensibilidad a la virtualidad apunta a algo más profundo que

deleuziana de música se recomienda la lectura del texto 'Devenir música' (Deleuze y Guattari, 2002, pp. 298-307).

${ }^{5}$ En la tercera edición de este texto (1937), Benjamin refiere precisamente el ensayo de Valery. una moda pasajera [...]. Es una característica implicada en el uso del lenguaje: somos capaces, por ejemplo, de ser transportados simbólicamente hacia otros lugares, imaginar lo que no está aquí (Lins Riveiro, en Winocur, 2010, p. 21).

\section{Del ritual colectivo a una experiencia de consumo individual}

La música ha pasado de constituir un ritual, una práctica comunicativa de presencias reales -de individuos presentes físicamente-, a una experiencia virtual de consumo individual sólidamente anclada en nuestra vida diaria.

Especialmente sugerentes resultan las páginas que el historiador holandés Johan Huizinga dedicó al carácter lúdico de la música en su libro Homo Ludens [1938]: «Nada como la sensibilidad musical nos puede impregnar del sentimiento de un juego sagrado» (2007, p. 202).

Los sistemas de grabación y reproducción sonora, la aparición de Internet y el desarrollo sin precedentes de las tecnologías de la comunicación, constituyen elementos decisivos para pensar la música en la actualidad. A continuación, me referiré a la experiencia musical como situación comunicativa. Para ello propongo partir de ese preciso instante en el que nos disponemos a escuchar, justo antes de que comience un concierto.

\section{El concierto como situación de comunicación. Dar(se) el silencio o «La música va a comenzar»}

Estoy en el concierto. Escucho. Aparte de escuchar, no hago otra cosa. He renunciado a la capacidad humana de decisión y de acción. No toco en la orquesta. ¿Soy «pasiva» por ello? En absoluto. Soy receptiva y siento esta receptividad como una actividad más intensa que muchas acciones o muchos esfuerzos. Se diría que, a través de la música, el tiempo mismo desplegara en mí una suerte de vida propia (Hersch, 2013, p. 16).

¿Qué nace exactamente cuando empieza la música? Al llegar la hora del concierto, el músico está a punto de comenzar la ejecución de su programa (la música se abre paso como situación de comunicación), se solicita implícita o explícitamente guardar silencio como condición 
de posibilidad para que el otro pueda así plegarse a la escucha: dar(se) el silencio para poder escuchar. Pero la calidad de este silencio no fue siempre como la que hoy se espera del público (una de las posibles líneas a desarrollar a partir de esta propuesta sería la del nacimiento y evolución histórica del silencio en una situación de concierto, en definitiva, como construcción social). En este sentido, Alain Corbin señala que:

A comienzos del siglo XIX saber callar, saber guardar silencio, frente a la algarabía en la que se complace el pueblo, forma parte del proceso de distinción, lo mismo que saber practicar el mezzo voce. Callar es también demostrar que uno se mantiene disponible para la escucha; tanto más porque en este siglo de las confidencias y de las afinidades electivas el silencio de quien sabe escuchar resulta muy valioso (2019, p. 70).

El silencio es recogimiento, y este alude a un lugar siempre interior. En su cara exterior, silencio y música se revelan como un bien público, se producen y se guardan de manera colectiva. El fenómeno musical como situación de comunicación nace directa o indirectamente con esa preparación solemne. El otro es testigo del nacimiento de una especie de nuevo lugar que inaugura, a su vez, múltiples horizontes: horizonte desplegado hacia el pasado, o memoria; horizonte de un presente que actualiza en cada instante un pasado ya dado y un futuro posible; y la proyección hacia adelante, horizonte de expectativas.

Pertenecemos al mundo habitándolo, vivimos en él con los otros. Este pensamiento, fuertemente presente en la co-relación hombremundo planteada por Husserl, permite hablar de "nuestro" mundo justamente porque lo habitamos en comunidad. La idea de mundo adquiere así el valor necesario de horizonte universal, esto es, el horizonte-mundo. La idea de un horizonte-mundo como transfiguración del contexto compensa de algún modo la ausencia de significado en la experiencia musical. La obra musical se erige así en horizonte compartido6.

\footnotetext{
${ }^{6}$ La idea de horizonte que aquí se explora en el marco de los modos de darse la experiencia musical, involucra a su vez la articulación de varios horizontes (la multiplicidad horizonte-mundo, horizonteotro, horizonte de experiencia, horizonte de expectativas), en línea con lo que Husserl propone en La crisis de las ciencias europeas y la
}

En su texto 'La existencia y el objeto', Simone Weil escribe: «La primera nota de una sonata comienza algo, pero ¿qué? En cuanto la oigo espero algo; algo que llegará infaliblemente» (2018, p. 48). Ese algo que comienza en la primera nota de una obra musical, ya sucede, en cualquier caso, en el otro como eventual lugar en el que existe, finalmente, la música. El tiempo del concierto, «que nos llevamos a casa, ya no tiene una extensión. Hay una parte de ese tiempo en mí que me hace vivir como jamás he vivido» (Hersch, 2013, p. 22).

\section{La importancia del gesto en la práctica musical}

Al pasar de la música como ritual a los sistemas de grabación y reproducción sonora se pierde algo importante: el gesto, elemento crucial en la rostreidad de la música. El gesto es el elemento pre-musical que la inaugura -y clausura- como situación de comunicación. Hasta la aparición de dichos sistemas, el gesto representaba el movimiento fundacional de ese otro lugar que inaugura la fórmula «la música va a comenzar». Trasladándonos del mundo cotidiano al mundo de la obra, el músico nos introduce en ella con un movimiento: la batuta arriba en el caso del director de orquesta, la preparación del cuerpo y de la mirada en el caso del solista. Adorno llamó la atención sobre la importancia de este aspecto de la interpretación: «En música no se trata de significado, sino de gestos. En tanto que la música es lenguaje, es un lenguaje sedimentado a partir de gestos» (2000, p. 69).

Ante la ausencia de cualquier otro tipo de potencial enunciativo, el gesto musical es necesariamente un elemento de afirmación. Con los sistemas de reproducción y grabación se desvanece este importante componente escénico, de la visualización de la música. El otro pierde el gesto del músico, y por tanto, un elemento decisivo en el contexto de la música como práctica comunicativa.

\section{A modo de conclusión}

La búsqueda de un sentido a la experiencia musical prosigue. Seguramente, las respuestas a

fenomenología trascendental: «[...] todo lo dado mundano es dado en el cómo de un horizonte, que en el horizonte hay implícitos otros horizontes, y finalmente cada uno como dado mundo trae consigo el horizonte de mundo y solo por ese medio es consciente como mundo» (2008, p. 300). 
las preguntas planteadas - ¿Dónde reside la esencia de una obra musical? ?¿Es esta búsqueda parte de la tarea filosófica? ¿Se puede traducir la música (es esto útil) de otro modo que no sea a través de metáforas, desterrando al propio sonido de la contestación? - nunca nos puedan satisfacer del todo: «Solo un espíritu temerario puede intentar abordar una explicación totalizadora de la música, pero es más temerario quien ni siquiera se plantea el problema» (Berio, 2019, p. 22). Aun así, debemos seguir interrogándonos indefectiblemente sobre los aspectos más esenciales y profundos de la experiencia musical, discutir las preguntas en ausencia de respuestas definitivas.

La conquista de la ubicuidad y la virtualización han difuminado, en cierto modo, los límites físicos del mundo como horizonte (el horizonte-mundo). La información-red ha sustituido a la realidad. En este nuevo contexto de desterritorialización de las presencias, resulta todavía más pertinente explorar la intersubjetividad como el lugar donde acontece, finalmente, la música.

Por su parte, la respuesta ofrecida por Schumann, sentarse de nuevo al piano e interpretar la obra por segunda vez, parece hoy insuficiente. En el mundo de la hipercomunicación, el músico es interpelado de manera recurrente a presentar y explicar su proceso creativo, llegando a confundirse su obra con la permanente narración en imágenes de su vida cotidiana. Los mensajes y referencias sobre la obra se integran en un lenguaje hipermedia a través del que se comparte toda una parafernalia que poco tiene que ver con la cosa misma. El ejemplo paradigmático de una actitud, vamos a decir, diferente a la del maestro alemán, es el de Stravinsky, quien al mismo tiempo que se inclinó por defender la incapacidad de la música para expresar nada en absoluto -en otras palabras, la música solo puede decir la cosa misma, esto es, lo único musicalmente esencial-, es por otro lado uno de los compositores que más ha escrito sobre el fenómeno musical. Esta actitud, más propia de una modernidad en desarrollo que del romanticismo tardío, sitúa la obra musical ante una especie de necesidad-deseo: parece tener que estar constantemente validada por un discurso verbal que actúe como moderador entre su apariencia y su esencia.

En la actualidad se habla mucho de momentos de ruptura, cambios de ciclo, modelos obsoletos, crisis de valores. La música prosigue en su calidad de lámpara y espejo (de la realidad social, de la historia, de las emociones... los reflejos son infinitos). Las tecnologías de la comunicación nos ofrecen toda una gama de herramientas creativas para hacer de nuestra propia vida la más bella forma de expresión artística. Ahora bien, insisto en esto: el arte como encuentro con el otro.

La música afecta de un modo directo el comportamiento humano. Por ello es importante conocer sus elementos constitutivos. Buscar un sentido al fenómeno musical desde el carácter íntimo e intransferible de la experiencia, pasa por poner en valor su dimensión ética, poética y comunicativa como base para una articulación con el otro. En este sentido, desde la centralidad que adquiere la conciencia de ese encuentro, todo arte es político. Por más que en ocasiones suponga la presencia de un rostro sin nombre, la necesidad del otro genera un particular sentimiento de compromiso. Una lectura ética y comunicativa de la experiencia musical nos abre las puertas al otro como horizonte. Hoy urge reivindicar desde la música la bella idea de Levinas: «Lo humano del hombre es desvivirse por el otro hombre». 


\section{Referencias}

Adorno, T. (2000). Sobre la música. Traducción de Gerard Vilar. Barcelona: Paidós.

- (2003). Filosofía de la nueva música. Traducción de Alfredo Brotons. Madrid: Akal.

Benjamin, W. (2003). La obra de arte en la época de su reproductibilidad técnica. Traducción de Andrés E. Welkert. México D.F.: Ítaca.

Berio, L. (2019). Un recuerdo al futuro. Traducción de Rosa Rius y Pere Salvat. Barcelona: Acantilado.

Born, G. (2011). Music and the materialization of identities. Journal of Material Culture 16(4), 376-388.

Charles, D. (1978). Le temps de la voix. Paris: JP Delarge.

Craft, R. (1991). Conversaciones con Igor Stravinsky (trad. de José María Martín Triana). Madrid: Alianza.

Corbin, A. (2019). Historia del silencio. Del Renacimiento hasta nuestros días (trad. de Jordi Bayod). Barcelona: Acantilado.

Dahl, P. (2019). Where is the essence of a musical work? En R. Staneviciuté, N. Zangwill, R. Povilionienè (eds.), Of Essence and Context. Between Music and Philosophy (pp. 197-211). Cham (Switzerland): Springer.

Deleuze, G. y Guattari, F. (2002). Mil mesetas. Capitalismo y esquizofrenia (trad. de José Vázquez Pérez y Umbelina Larraceleta). Valencia: Pre-Textos.

Dewey, J. (2005). Art as Experience. New York: Penguin.

Fubini, E. (2007). Música y estética en la época medieval (ed. y trad. de textos latinos a cargo de Cecilia Criado). Pamplona: EUNSA.

Heidegger, M. (1991). La proposición del fundamento (trad. de Félix Duque y Jorge Pérez de Tudela). Barcelona: Ediciones del Serbal.

Hersch, J. (2013). Tiempo y música (trad. de Rosa Rius y Ramón Andrés). Barcelona: Acantilado.

Hobsbawm, E. (2013). Un tiempo de rupturas. sociedad y cultura en el siglo XX (trad. de Cecilia Belza y Gonzalo García). Barcelona: Crítica.

Huizinga, J. (2007). Homo ludens (trad. de Eugenio Imaz). Madrid: Alianza.

Husserl, E. (2008). La crisis de las ciencias europeas y la fenomenología trascendental (trad. y estudio preliminar de Julia V. Iribarne). Buenos Aires: Prometeo.

Lejeune, P. (1975). Le pacte autobiographique. Paris: Seuil.

Lippman, A. (1964). Musical Thought in Ancient Greece. New York: Columbia University Press.

Steiner, G. (2007). Los logócratas (trad. de María Condor). México D.F.: Fondo de Cultura Económica; Siruela.

- (2012). La poesía del pensamiento (trad. de María Condor). Buenos Aires: Fondo de Cultura Económica; Siruela.

Stravinsky, I. (2005). Crónicas de mi vida (trad. de Elena Vilallonga Serra). Barcelona: Alba.

Valery, P. (1999). Piezas sobre arte. (trad. de José Luis Arántegui). Madrid: Visor.

Weil, S. (2018). Primeros escritos filosóficos (trad. de Teresa Escartín y José Luís Escartín). Madrid: Trotta.

Winocur, R. (2010). Robinson Crusoe ya tiene celular. México D.F.: Siglo XXI. 